\title{
Analisis Potensi Daya Listrik Pada Sumur Produksi Panas Bumi Dengan Mengunakan Metode
} Back Pressure Pada Unit XY

\author{
Richa Melysa ${ }^{1}$, Fitrianti ${ }^{1}$ \\ ${ }^{1}$ Program Studi Teknik Perminyakan Universitas Islam Riau
}

\begin{abstract}
As the increasing demand of energy in indonesia, PT.Pertamina Geothermal Energy area Kamojang that is one of the companies which are engaged in geothermal power plant which contributed the need for electricity domestic with a total capacity of $235 \mathrm{MW}$ with consisting of 5 units of steam power plants electricity.But to produce the electrical power needs to be done a calculation about the potential electrical power for every production wells, so it is necessary to do back pressure production test for every production wells.Back pressure production test was conducted to obtain capability of geothermal production well, it is necessary to know the output curve of well production, back pressureproductionproduction test done by closing the wells first untill wellhead pressure reach a stability and then produce well with setting wellhead pressure at different wellhead pressure until it achieve stability for each setting of the wellhead pressure. The result of back pressure production test for every production wells in unit "XY" that the maximum mass flowof XY-1, XY-2, XY-3, and XY-4 wells at $10 \mathrm{~kg} / \mathrm{cm}^{2}$ are 28,49 tons/hour, 103,72 tons/hour, 175,31 tons/hour and 68,97 tons/hour. So the maximum potential for unit "XY" is $50 \mathrm{MW}$ with total mass flow is about $373,04 \mathrm{~kg} / \mathrm{cm}^{2}$.
\end{abstract}

Keywords: Production test, Back pressure, Output curve, Wellhead pressure

Corresponding Author e-mail address: richamelysa@eng.uir.ac.id

\section{PENDAHULUAN}

Pembangkit listrik tenaga panas bumi (PLTP) di Indonesia belum banyak dikembangkan dan dimanfaatkan. Padahal dengan potensi pembangkit sebesar 28.100 MW, Indonesia memiliki sekitar $40 \%$ dari cadangan energi panas bumi dunia. Dari jumlah tersebut, hanya sekitar $4 \%$ dari total potensi yang telah dimanfaatkan sebagai pembangkit listrik tenaga panas bumi (PLTP) yaitu sebesar 1.197 MW Di mancanegara, PLTP sudah banyak dibangun dan dikembangkan. Amerika Serikat mengadakan riset tentang Enhanced Gheothermal System (EGS) yang bertujuan memaksimalkan pemanfaatan panas bumi yang ada.

Pemanfaatan panas bumi dapat turut menunjang pembangunan nasional untuk mewujudkan kesejahteraan masyarakat. Salah satunya lapangan panas bumi Kamojang, daerah panas bumi Kamojang terletak $40 \mathrm{~km}$ di sebelah selatan Bandung, Jawa Barat. Daerah Kamojang memiliki ketinggian 1,730 meter dari permukaan laut. Koordinat $7^{\circ} 07^{\prime} 30^{\prime \prime} \mathrm{S} 107^{\circ} 48^{\prime} 00^{\prime \prime} \mathrm{E} / 7^{\prime} 125^{\circ} \mathrm{LS} 107.8^{\circ} \mathrm{BT}$. Penyelidikan dan pengamatan geologi, geofisik serta geokimia telah menemukan daerah penghasil panas bumi seluas $14 \mathrm{~km}^{2}$ di daerah Kamojang. Dari penyelidikan tersebut diperkirakan terdapat sumber panas bumi yang dapat menghasilkan 100-200 MW energi listrik selama 25 tahun. Uap yang dihasilkan di Kamojang ini memiliki tipe uap kering. Artinya kandungan air dalam uap relatif sedikit. Beberapa lokasi di Kamojang telah dilakukan proses pengeboran. Dengan kedalaman 1.000-1.500 m pengeboran telah didapat rata-rata uap sebesar 20-110 ton/jam. 
Siklus Direct Dry Steam merupakan siklus uap langsung tanpa penggunaan separator pemisah fasa uap dan cair sehingga uap yang bertekanan tinggi akan langsung dialirkan dari reservoir menuju pembangkit listrik yaitu turbin. Saat memproduksikan uap tersebut, tekanan pada reservoir sangat mempengaruhi jumlah produksi uap yang akan dihasilkan dari suatu sumur produksi, jumlah massa uap yang mengalir ke permukaan menentukan besarnya potensi daya listrik turbin uap yang dapat dihasilkan, sehingga perlu dilakukan analisis terhadap laju produksi dari suatu sumur produksi agar dapat mengahsilkan daya listrik yang diharapkan pada sebuah turbin uap. Analisis produksi dapat dilakukan dengan melakukan uji produksi atau biasa disebut output test, uji produksi pada suatu sumur panas bumi bertujuan untuk mengetahui deliverability, yaitu kemampuan suatu sumur untuk menghantarkan fluida kepermukaan. Pada dasarnya ada beberapa macam metode uji produksi yang dapat digunakan untuk memperoleh deliverability, yaitu Uji Datar, Uji Tegak, Uji Kalorimeter dan Uji Separator. Untuk mengetahui deliverabilitas suatu sumur metode uji produksi yang digunakan untuk sumur-sumur di lapangan Kamojang adalah metode Uji Datar. Pemilihan metode uji datar yang dilakukan di lapangan kamojang berdasarkan pada keakuratan dalam menentukan kapasitas produksi atau deliverability sumur.

Pada penelitian akan melakukan analisis dari sumur-sumur produksi yang ada pada unit $\mathrm{XY}$ yaitu sumur XY-1, XY-2, XY-3, dan XY-4 dengan melakukan analisis data terhadap hasil data uji produksi back pressure yang telah dilakukan pada sumur sumur produksi unit $\mathrm{XY}$ untuk mengetahui potensi daya listrik untuk sumur-sumur produksi tersebut.

\section{METODE PENELITIAN}

Back pressure merupakan suatu metode test sumur gas untuk mengetahui kemampuan sumur berproduksi dengan memberikan tekanan balik (Back Pressure) yang berbeda-beda. Pelaksanaan dari test konvensional ini dimulai dengan menstabilkan tekanan reservoir dengan cara menutup sumur lalu ditentukan harga $P_{R}$. Selanjutnya sumur diproduksi diubah-ubah empat kali dan setiap kali sumur itu dibiarkan berproduksi sampai tekanan mencapai stabil sebelum diganti dengan laju produksi lainnya. Setiap perubahan laju produksi tidak didahului dengan penutupan sumur. Gambar skematis dari proses back pressure diperlihatkan pada gambar di bawah:

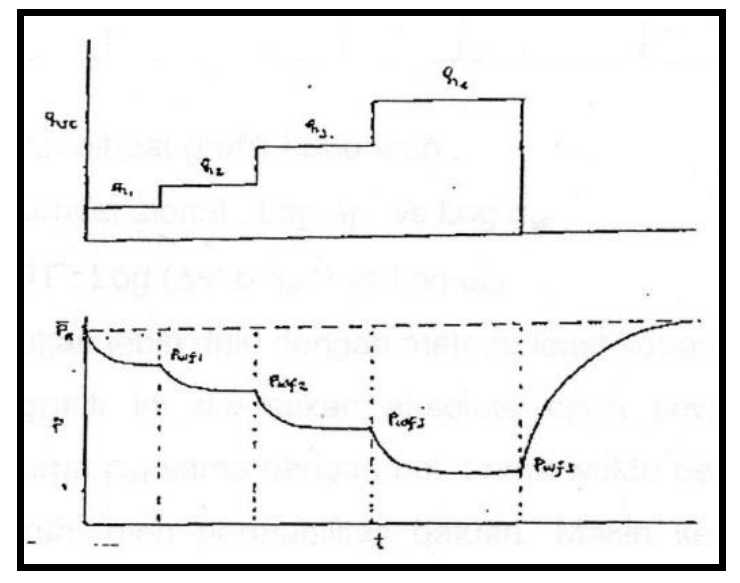

Gambar 1 Skema Tekanan dan Laju Alir pada Uji Back Pressure 
Analisis deliverability didasarkan pada kondisi aliran yang stabil. Untuk keperluan ini diambil tekanan alir dasar sumur, $P_{w f}$, pada akhir perioda suatu laju produksi. Pada gambar sebelumnya dinyatakan oleh $P_{w f x}$. Analisis data untuk keperluan pembuatan grafik deliverability didasarkan pada metode konvensional.

\section{HASIL DAN PEMBAHASAN}

Dalam penelitian ini penulis melakukan perhitungan dan analisis terhadap empat sumur satu fasa uap pada unit XY, sumur XY-1 menggunakan konfigurasi 1 dan sumur XY-2, XY-3 dan XY-4 menggunakan konfigurasi 2, uji produksi yang dilakukan pada sumur-sumur tersebut memakai metode back pressure test. Analisis uji datar dimaksudkan untuk mencari nilai " $\mathrm{n}$ " dan " $\mathrm{C}$ " yang selanjutnya akan dimasukan ke dalam persamaan deliverability dan kurva output produksi dari masing masing sumur.

\section{Menentukan output curve sumur XY-1}

Pencarian nilai $\mathrm{C}$ dan $n$ pada Sumur-sumur unit $\mathrm{XY}$ dilakukan dengan membuat plot $\log q$ vs $\log \Delta \mathrm{P}^{2}$. Berikut merupakan hasil uji back pressure pada sumur XY-1 dengan menggunakan pipa 8" SCH 40:

Tabel 1 Hasil uji back pressure sumur XY-1 untuk beberapa nilai $P_{w h}$

\begin{tabular}{cc}
\hline$P_{\text {wf }}\left(\mathbf{k g} / \mathbf{c m}^{2}\right)$ & $\mathbf{q}(\mathbf{t o n} / \mathbf{j a m})$ \\
\hline 5,3 & 31.13 \\
\hline 10,2 & 27,56 \\
\hline 12,7 & 26,89 \\
\hline 25 & 0 \\
\hline
\end{tabular}

Dari data uji back pressure diatas kemudian kita mencari nilai $\log q$ dan $\log \Delta \mathrm{P}^{2}$, nilai $\Delta \mathrm{P}^{2}$ di dapat dari pengurangan antara $P_{w h}$ maksimum dengan $P_{w h}$ uji karena nilai $P_{w h}$ maksimum dianggap sebagai tekanan reservoir.

Tabel 2 Hasil perhitungan nilai $\log q$ dan $\log \Delta \mathrm{P}^{2}$ sumur XY-1

\begin{tabular}{ccccc}
\hline$P_{\text {wf }}\left(\mathbf{k g} / \mathbf{c m}^{2}\right)$ & $\mathbf{q}($ ton/jam) & $\Delta P^{2}\left(\mathbf{k g} / \mathbf{c m}^{2}\right)$ & $\log \mathbf{q}$ & $\log \Delta P^{2}$ \\
\hline 5,3 & 31,13 & 596,91 & 1,49 & 2,78 \\
\hline 10,2 & 27,56 & 520,96 & 1,44 & 2,72 \\
\hline 12,7 & 26,89 & 463,71 & 1,43 & 2,67 \\
\hline
\end{tabular}

Dari tabel 2 dapat dicari nilai $\mathrm{C}$ dan $n$ dengan memplot nilai nilai $\log q$ dan $\log \Delta \mathrm{P}^{2}$ sehingga didapat nilai $\mathrm{C}$ dan nilai $n$ yang kemudian dimasukkan kedalam persamaan deliverability untuk menetukan output curve produksi sumur XY-1 untuk beberapa nilai $P_{\text {wh }}$ yang berbeda. 


\section{SUMUR XY-1}

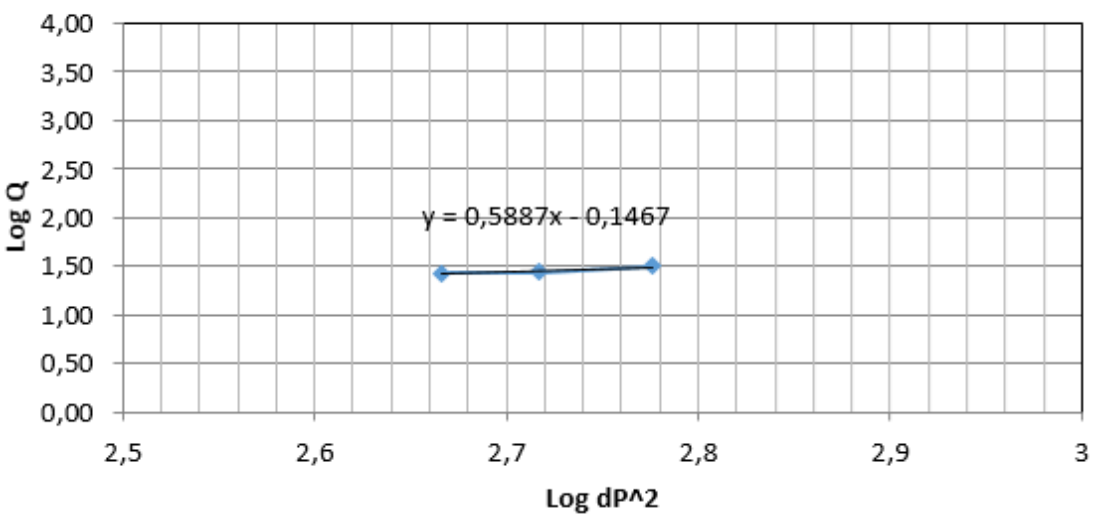

Gambar 2 Plot Log-log untuk Menentukan Nilai C dan $n$ Sumur XY-1

Berdasarkan kurva log gambar 2 didapatkan nilai $\mathrm{C}=10^{-0,1467}=0,713346$ sedangkan nilai $\mathrm{n}=0,5887$ sehingga output curve untuk sumur XY-1 didapatkan dari persamaan deliverability.

SUMUR XY-1

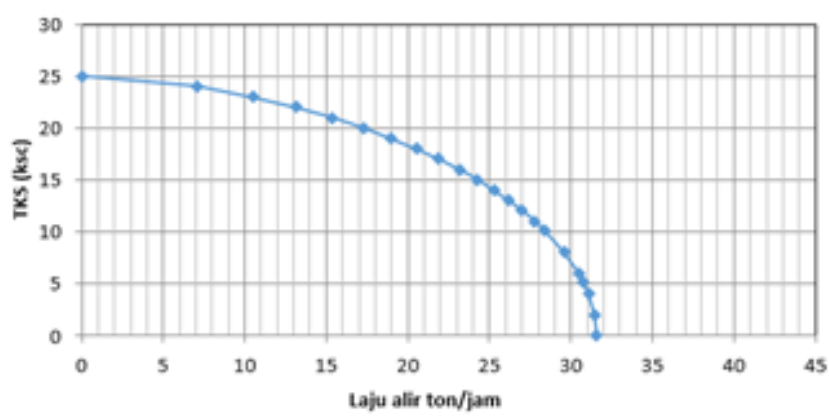

SUMUR XY-3

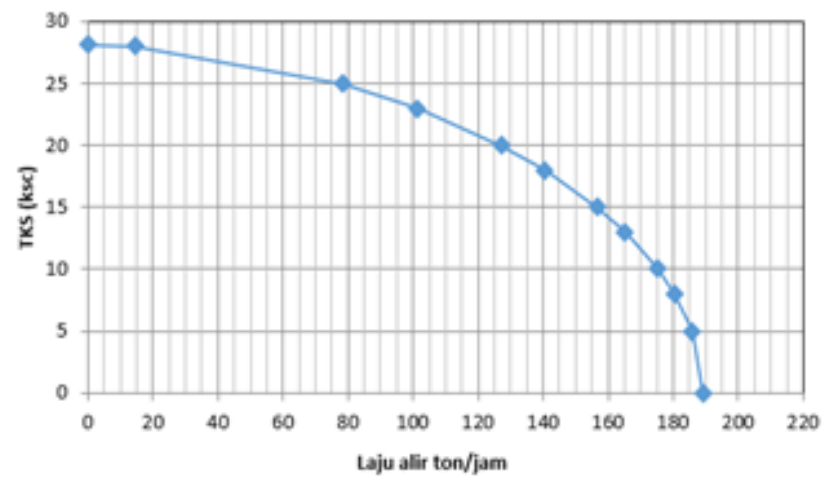

SUMUR XY-2

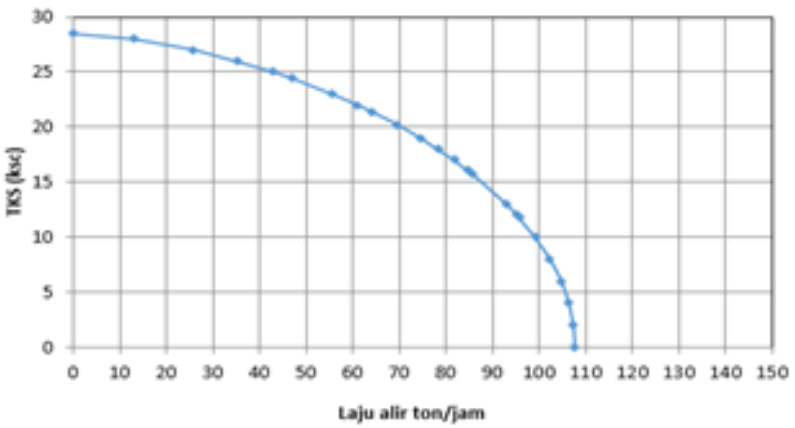

SUMUR XY-4

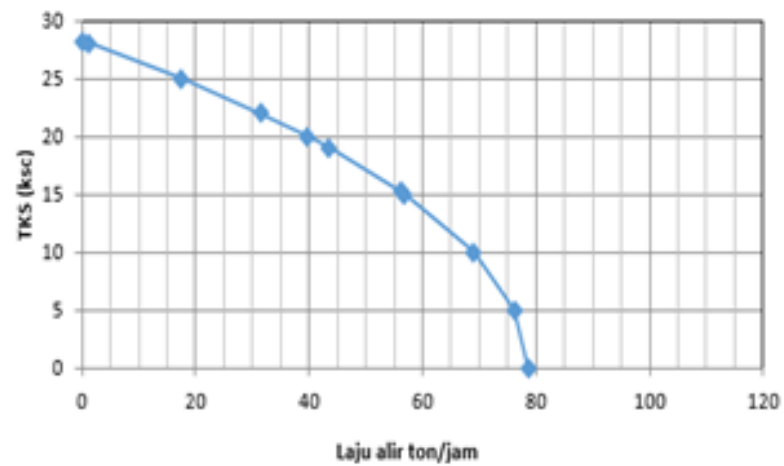

Gambar 3 Hasil Output Curve Untuk Sumur Pada Unit XY

Dari output curve sumur-sumur produksi pada unit XY jika ditabelkan dalam bentuk potensi sumur maka akan didapatkan tabel sebagai berikut: 
Tabel 3 Hasil output curve pada sumur-sumur produksi unit XY

\begin{tabular}{cccccccc}
\hline \multicolumn{2}{r}{$\mathbf{X Y - 1}$} & \multicolumn{2}{c}{$\mathbf{X Y - 2}$} & \multicolumn{2}{c}{$\mathbf{X Y - 3}$} & \multicolumn{2}{c}{$\mathbf{X}-4$} \\
\hline $\begin{array}{c}P_{\text {wf }} \\
\left(\mathbf{k g} / \mathbf{c m}^{2}\right)\end{array}$ & $\begin{array}{c}\mathbf{q} \\
(\mathbf{t o n} / \mathbf{j a m})\end{array}$ & $\begin{array}{c}P_{\text {wf }} \\
\left(\mathbf{k g} / \mathbf{c m}^{2}\right)\end{array}$ & $\begin{array}{c}\mathbf{q} \\
(\mathbf{t o n} / \mathbf{j a m})\end{array}$ & $\begin{array}{c}P_{\text {wf }} \\
\left(\mathbf{k g} / \mathbf{c m}^{2}\right)\end{array}$ & $\begin{array}{c}\mathbf{q} \\
(\mathbf{t o n} / \mathbf{j a m})\end{array}$ & $\begin{array}{c}P_{\text {wf }} \\
\left(\mathbf{k g} / \mathbf{c m}^{\mathbf{2}}\right)\end{array}$ & $\begin{array}{c}\mathbf{q} \\
(\mathbf{t o n} / \mathbf{j a m})\end{array}$ \\
\hline $\mathbf{0}$ & 31,57 & 0 & 109,71 & 0 & 189,21 & 0 & 78,63 \\
\hline $\mathbf{5}$ & 30,82 & 5 & 107,39 & 5 & 185,81 & 5 & 76,22 \\
\hline $\mathbf{8}$ & 29,62 & 8 & 103,72 & 8 & 180,41 & 8 & 72,45 \\
\hline $\mathbf{1 0}$ & 28,49 & 10 & 100,27 & 10 & 175,31 & 10 & 68,97 \\
\hline $\mathbf{1 3}$ & 26,22 & 13 & 93,51 & 13 & 165,20 & 13 & 62,29 \\
\hline $\mathbf{1 5}$ & 24,27 & 15 & 87,86 & 15 & 156,63 & 15 & 56,85 \\
\hline $\mathbf{1 8}$ & 20,53 & 18 & 77,43 & 18 & 140,53 & 18 & 47,20 \\
\hline $\mathbf{2 0}$ & 17,30 & 20 & 68,95 & 20 & 127,14 & 20 & 39,76 \\
\hline $\mathbf{2 3}$ & 10,48 & 23 & 53,33 & 23 & 101,48 & 23 & 27,05 \\
\hline $\mathbf{2 5}$ & 0,00 & 25 & 40,17 & 25 & 78,53 & 25 & 17,49 \\
\hline- & - & 28 & 11,00 & 28 & 14,47 & 28 & 1,24 \\
\hline- & - & 28,5 & 0,00 & 28,15 & 0,00 & 28,2 & 0,00 \\
\hline
\end{tabular}

\section{Laju Alir Massa Uap Turbin}

Pada unit XY digunakan turbin dengan kapasitas 35 MW dengan demikian maka menghitung laju alir massa yang dibutuhkan oleh turbin untuk menghasilkan daya listrik tersebut adalah sebagai berikut: Untuk membangkitkan daya listrik sebesar $35 \mathrm{MW}$ dengan tambahan 2MW untuk daya listrik power plant pada unit XY dibutuhkkan laju alir massa sebesar 273,19 ton/jam, sehingga dilakukan pengaturan laju alir massa untuk sumur-sumur unit XY agar total laju alir massa yang masuk ke turbin sebesar 273,19 ton/jam.

\section{Potensi sumur produksi pada unit XY}

Dengan menggunakan hasil perhitungan laju alir massa kita dapat memperkirakan potensi dari suatu sumur produksi dengan mengkonversikan laju alir massa terhadap daya turbin :

$\begin{array}{llll}37 \mathrm{MW} & =273,19 \mathrm{ton} / \mathrm{jam} ; & 32,47 \mathrm{MW} & =240,26 \mathrm{ton} / \mathrm{jam} \\ \mathrm{maka} & & & \\ 1 \mathrm{MW} & =7,38 \mathrm{ton} / \mathrm{jam} ; & 1 \mathrm{MW} & \end{array}$

Dengan mempertimbangkan pressure drop pada pipa alir pada unit ini yang bernilai sekitar 2,5 - 3 $\mathrm{kg} / \mathrm{cm}^{2}$ dan tekanan inlet turbin sebesar $6,6 \mathrm{~kg} / \mathrm{cm}^{2}$ makapengaturan $P_{\text {wh }}$ maksimum harus lebih besar dari $9,1-9,6 \mathrm{~kg} / \mathrm{cm}^{2}$ yaitu pada $10 \mathrm{~kg} / \mathrm{cm}^{2}$ sehingga unit "XY" akan menghasilkan laju alir massa total 273,04 ton/jam dengan daya listrik sebesar $50 \mathrm{MW}$ dengan energi uap terbuang sebesar 4 ton/jam. 


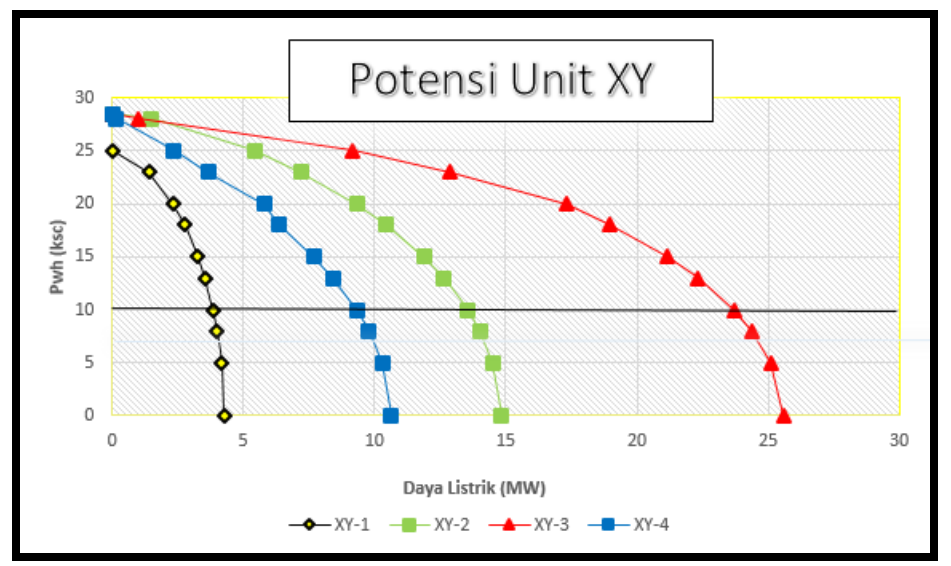

Gambar 4 Grafik Potensi Daya listrik Unit XY dengan pengaturan $10 \mathrm{~kg} / \mathrm{cm}^{2}$

Dari gambar grafik potensi unit $X Y$ dengan pengaturan tekanan kepala sumur $10 \mathrm{~kg} / \mathrm{cm}^{2}$ akan didapatkan alir massa sumur XY-1, XY-2, XY-3 dan XY-4 adalah 28,49 ton/jam, 100,27 ton/jam, 175,31 ton/jam dan 68,97 ton/jam. Dengan laju alir massa tersebut akan didapatkan potensi daya listrik untuk setiap sumur XY-1, XY-2, XY-3 dan XY-4 sebesar 3,85 MW, 13,55 MW, 23,69 MW dan 9,32 MW seperti pada gambar grafik yang ada di bawah ini.

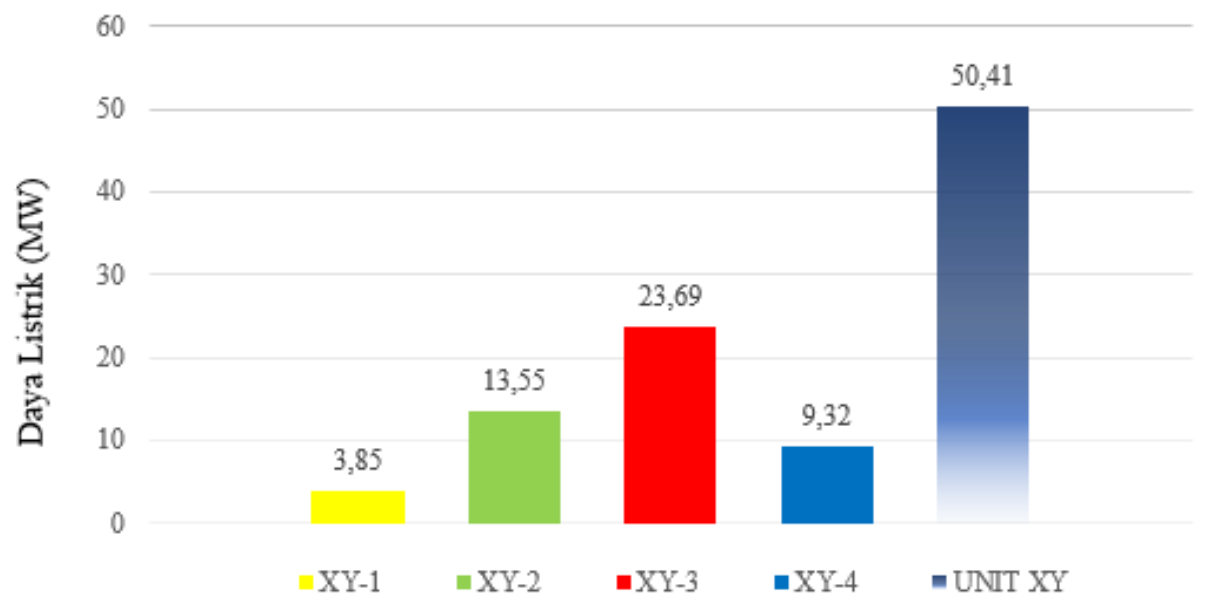

Gambar 5 Potensi maksimum unit XY dengan pengaturan $P_{w h} 10 \mathrm{~kg} / \mathrm{cm}^{2}$

Unit "XY" merupakan unit pembangkit listrik dengan kapasitas $35 \mathrm{MW}$ yang memiliki empat sumur produksi, penentuan laju alir massa pada suatu unit sangat diperlukan agar tidak adanya energi panas bumi yang terbuang sia-sia. Untuk membangkitkan daya listrik sebsar 37 MW dibutuhkan sekitar 273,19 ton uap perjamnya, nilai ini didapatkan dengan menghitung laju alir massa dari persamaan untuk menentukan daya turbin $\left(W_{t}\right)$, setelah mendapatkan nilai laju alir massa yang dibutuhkkan maka nilai tersebut dapat dikonversikan dengan daya listrik yang dihasilkan sehingga didapatkan 7,38 atau 7,39 ton uap perjam untuk satu MW. 
Setelah mengetahui jumlah laju alir massa yang dibutuhkan untuk menghasilkan daya listrik sebesar satu MW, maka dapat pula dihitung potensi yang bisa dihasilkan dari sumur-sumur produksi pada unit "XY". Dari tabel output curve sumur produksi pada bab sebelumnya dapat dilihat potensi dari setiap sumur produksi yang ada pada unit "XY", dengan melakukan pengaturan tekanan kepala sumur yang sesuai maka sumur-sumur produksi unit "XY" ini dapat menghasilkan daya listrik yang diharapkan, sebagai contoh untuk menghasilkan daya listrik 37 MW maka tekanan kepala sumur produksi dari setiap sumur diatur sebesar $18,5 \mathrm{~kg} / \mathrm{cm}^{2}$ sehingga total laju alir masssa sebesar 278,04 ton/jam. Potensi sumur-sumur produksi pada unit ini dapat menghasilkan daya listrik sebesar $50 \mathrm{MW}$ dengan mengatur tekanan kepala sumur $10 \mathrm{~kg} / \mathrm{cm}^{2}$ maka laju alir massa total uap yang dihasilkan sebesar 373,04 ton/jam, penentuan tekanan kepala sumur maksimal sebesar $10 \mathrm{~kg} / \mathrm{cm}^{2}$ ini ditentukan berdasarkan dengan kondisi pressure drop yang terjadi pada pipa alir produksi sebesar $2,5-3 \mathrm{~kg} / \mathrm{cm}^{2}$ dan kondisi tekanan inlet turbin sebesar $6,6 \mathrm{~kg} / \mathrm{cm}^{2}$ sehingga nilai tekanan kepala sumur yang maksimum yang diperbolehkan harus lebih besar dari $9,1-9,6 \mathrm{~kg} / \mathrm{cm}^{2}$.

\section{KESIMPULAN}

Setelah melakukan perhitungan dari data-data yang tersedia dari lapangan maka dapat diambil kesimpulan, yaitu :

1. Dari data uji produksi back pressure pada unit "XY" didapatkan output curve dari setiap sumursumur produksi yang ada pada unit tersebut. Berdasarkan pertimbangan kondisi pressure drop dan tekanan inlet turbin maka pengaturan tekanan kepala sumur maksimum $10 \mathrm{~kg} / \mathrm{cm}^{2}$ didapatkan nilai laju alir maksimum untuk sumur XY-1, XY-2, XY-3 dan XY-4 adalah 28,49 ton/jam, 100,27 ton/jam, 175,31 ton/jam dan 68,97 ton/jam.

2. Perhitungan laju alir massa yang didapatkan untuk menghasilkan daya $1 \mathrm{MW}$ dibutuhkan sekitar 7,39 ton/jam, sehingga potensi setiap sumur produksi pada unit "XY" untuk pengaturan tekanan kepala sumur maksimum $10 \mathrm{~kg} / \mathrm{cm}^{2}$ adalah 373,04 ton/jam dengan daya sebesar 50 MW dan energi uap terbuang sebesar 4 ton/jam.

\section{DAFTAR PUSTAKA}

Acuna, J.A. \& Pasaribu, F. (2010). Improved Method for Decline Analysis of Dry Steam Well. The 2010 World Geothermal Congress, Bali.

Beggs, H.D. (1991). Production Optimization Using Nodal Analysis. Tulsa, Oklahoma: OGCI and Petroskills Publications.

Bodvarsson, G.S. \&Whiterspoon, P.A. (1989). Geothermal Reservoir Engineering. Journal of Geotherm. Sci. \& Tech., Vol 2.

Direktorat Jendral Mineral, Batubara dan Panas Bumi. (2010). WARTA Mineral, Batubara dan Panas Bumi. Jakarta.

Okandan, Ender. (1997). Geothermal Reservoir Engineering. Ankara: Middle East Technical University

Grant, M.A., Donaldson, I.G. \& Bixley, P.F. (1982). Geothermal Reservoir Engineering. New York: Academic Press.

Hochstein, M.P. (1990). Clasification and Assesment of Geothermal Resources. A Guide to Development and Utilization, UNITAR p. 31-57. New York.

Martodjojo, S. (1984). Evolusi Cekungan Bogor Jawa Barat. Disertasi. Bandung: Institute Teknologi Bandung.

Pri, Utami. (1998). Energi Panas Bumi: Sebuah Gambaran Umum. Jurnal Energi Vol. 2. 
Haryono, S. (2012). Pola Sistem Panas dan Jenis Geothermal dalam Estimasi Cadangan Daerah Kamojang. Jurnal Ilmiah MTG vol 5 no 2 